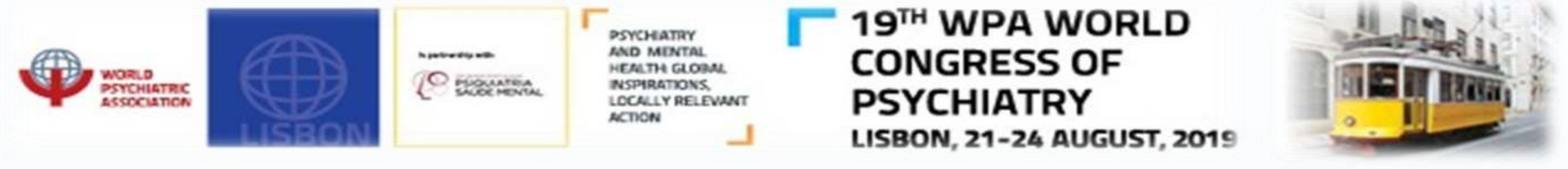

\title{
The use of the new technologies in psychotherapeutic treatments: a review
}

ALVES, C.G.; VARANDA, C.A. - Universidade Paulista

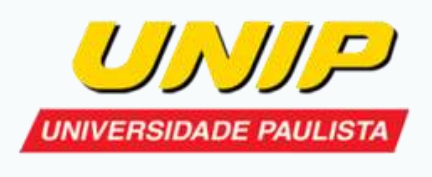

INTRODUCTION: Significant changes have been made in society, making technology devices an important part of our lives, changing how social relationships are made, perceptions, behavioral patterns, thus, creating a new identity and way of life to the individual [01]. This work focuses on the ones that seek to interconnect technology and available scientific knowledge, aiming to help and create a better psychological care, also reaching a bigger radius of action. This concept is called E-Mental Health, which can be used in a variety of ways, such as apps and web.

METHOD: This research was a bibliographical review which selected scientific publications, written in Portuguese and English, between 2013 and 2018, published in PUBMED, LILACS, SciELO and Google Scholar databases, excluding bibliographic reviews, researches that do describe the use of the new technologies of information as a tool in psychotherapeutic treatments and articles with no free access.

RESULTS: A total of 192 articles were found, and after considering the exclusion criteria, 15 articles were considered for analysis.



DISCUSSION: Most of the studies found were from the US and Germany, with the rest of the articles coming from other European countries. Only two articles were from Brazil.

\section{ARTICLES FOUND BY COUNTRIES}

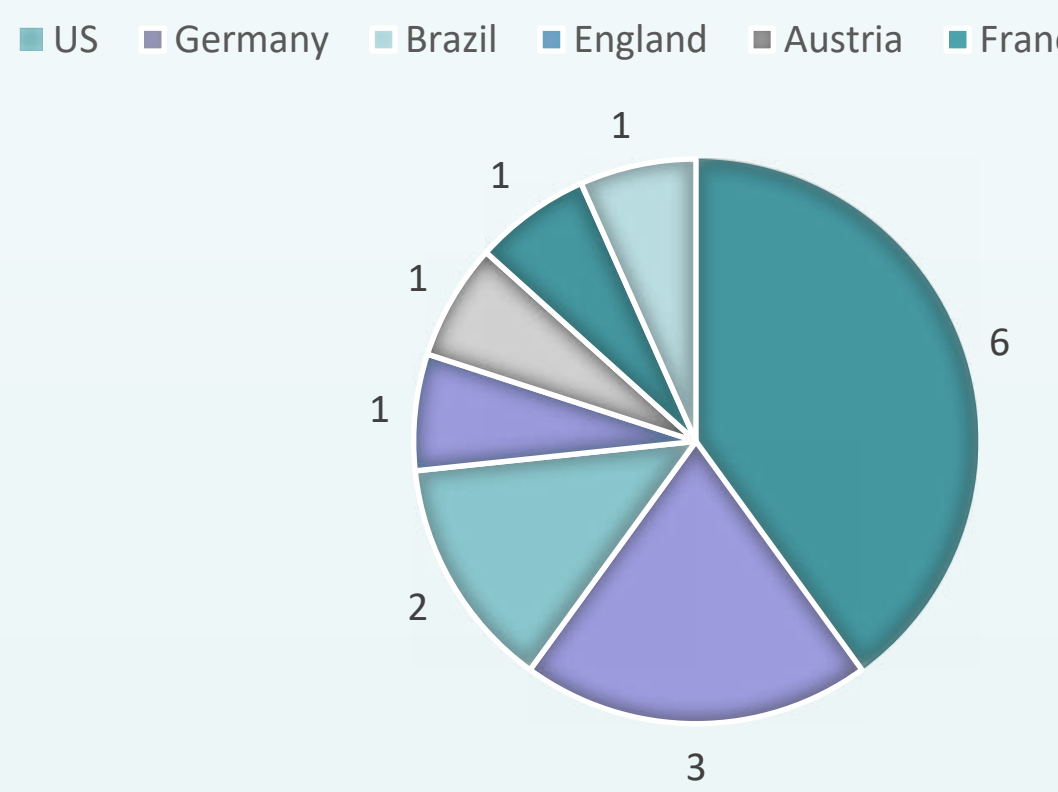

Six of fifteen studies were randomized controlled trials, with five survey studies, followed by transversal studies, with two, and a feasibility study and card sorting task study, with one each.

\section{TYPES OF STUDIES AND THEIR} OUTCOMES

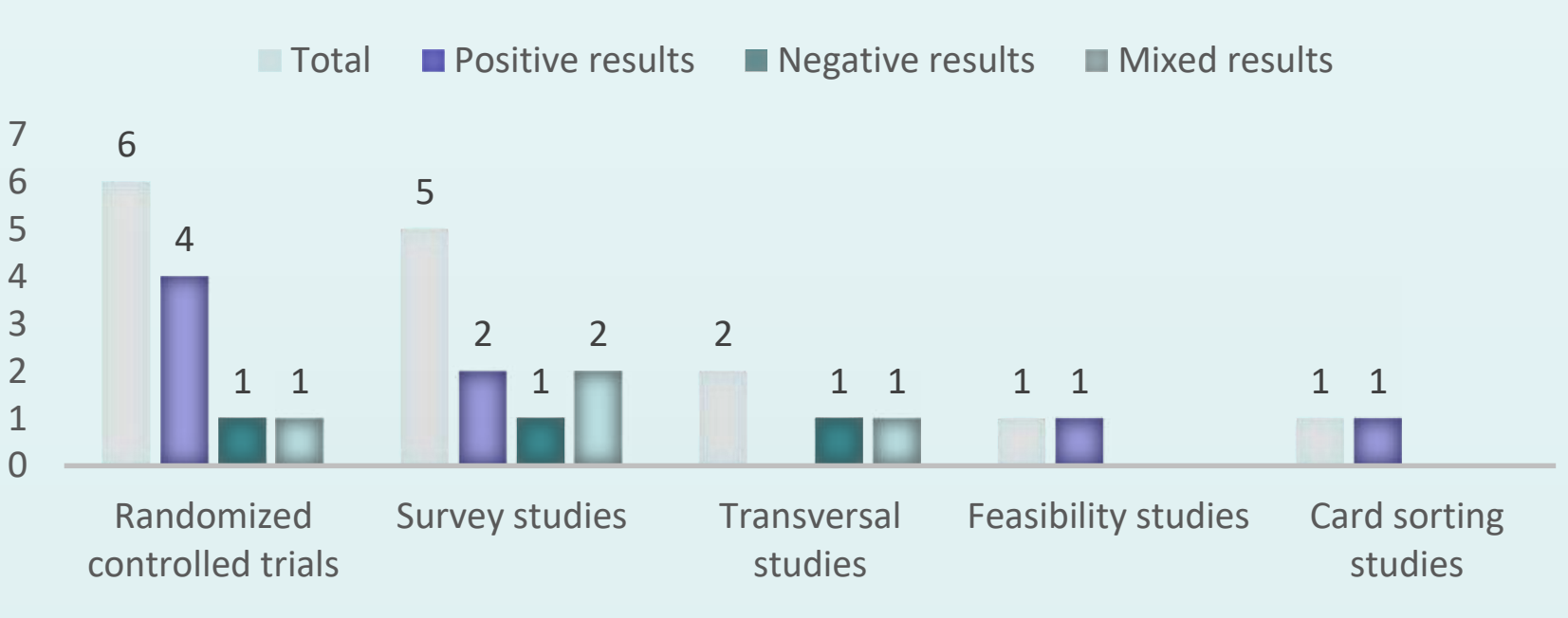

The majority of the studies indicate that EMental Health can be used in the psychotherapeutic environment, as a alternative or as a tool combined with face-toface therapy.

\section{REFERENCES}

[01] LEVISKY, R.B.; SILVA, M.C.R. A invasão das novas formas de comunicação no setting terapêutico. Vínculo, v.7, n.1 São Paulo, Jun. 2010.2 Disponível em:<http://pepsic.bvsalud.org/scielo.php?script=sci_arttext\&pid=S180624902010000100008> 